\section{Surgeon-Performed \\ Ultrasound Can Predict \\ Differentiated Thyroid \\ Cancer in Patients with Solitary Thyroid Nodules}

\section{TO THE EDITORS:}

We had read this article with interest and want to congratulate Dr. Jabiev and his team for their approach in predicting differentiated thyroid cancer in patients with solitary thyroid nodules. ${ }^{1}$ However, we would like to have more clarification on few points.

$\mathrm{Had}$ the authors performed preoperative FNAC in these patients and compared the results with surgeonperformed ultrasound findings? If so, what were their findings? Cappelli et al. described the predictive value of ultrasonographic findings and compared them with cytology results in thyroid nodules and found that microcalcifications were the strongest predictor for malignancy. ${ }^{2}$ They also found that Type 2 vascularity (intranodular flow with multiple vascular images) and size are also statistically significant predictors for malignancy. Also we would like to know whether intraoperative frozen section biopsies were done in these patients. If so, what was the indication? Moon et al. combined ultrasound and intraoperative frozen section in patients of papillary thyroid carcinomas, concluding that frozen section should be used when the features on ultrasound do not predict malignancy. ${ }^{3}$

Had the authors compared their ultrasonographic findings with the radiologist-performed ultrasound findings and could they find that surgeon-performed ultrasound is better than radiologist-performed ultrasound? If yes, in what way and what is their recommendation? A patient with thyroid nodule should undergo radiologist-performed ultrasound or not, if facility for both; surgeon-performed as well as radiologist-performed ultrasound is available?

\section{Ritesh Agrawal, Sudhi Agarwal, and Gyan Chand} Department of Endocrine Surgery, Sanjay Gandhi Post Graduate Institute of Medical Sciences, Lucknow, India e-mail: gyan133@sgpgi.ac.in

Published Online: 19 May 2010

(C) Society of Surgical Oncology 2010

\section{REFERENCES}

1. Jabiev AA, Ikeda MH, Reis IM, Solorzano CC, Lew JI. Surgeonperformed ultrasound can predict differentiated thyroid cancer in patients with solitary thyroid nodules. Ann Surg Oncol. 2009; 16:3140-5.

2. Cappelli C, Casellano M, Pirola I, Cumetti D, Agosti B, Gandossi $\mathrm{E}$, et al. The predictive value of ultrasound findings in the management of thyroid nodules. QJM. 2007;100:29-35.

3. Moon HJ, Kwak JY, Kim EK, Kim MJ, Park CS, Chung WY, et al. The combined role of ultrasound and frozen section in surgical management of thyroid nodules read as suspicious for papillary thyroid carcinoma on fine needle aspiration biopsy: a retrospective study. World J Surg. 2009;33:950-7. 